\title{
Sexualidad y disidencia en la obra de Fernando Arrabal
}

\section{Sexuality and Dissent in Fernando Arrabal's Work}

\author{
Domingo Pujante González \\ Universitat de València \\ domingo.pujante@uv.es
}

\begin{abstract}
In this article, we aim to analyse the presence and the importance of non-normative sexualities, those which escape the reproductive function, in Fernando Arrabal's work, a Spanish author, born in Melilla in 1932, exiled in Paris where he has lived since 1955 . The work is divided into three parts and a conclusion: first, we will expose the existing link between Eros and Thanatos in order to elucidate the association that is established between eroticism and death pulsion, and between love and suffering in his work; then, we will approach the Homosexual Desire in order to expose the narcissistic and sadomasochistic aspects of this fascination which appear in Arrabal's creation; finally, in the third part entitled Phallic Pleasures, we will focus on some sexual practices such as masturbation and fellatio to show the symbolic and "panic" value that they acquire in the creation of the author. Thus, we will prove that Arrabal, as a committed author, is trying to get rid of the repression that authoritarian regimes exert on people expressing dissident sexuality. To illustrate our remarks, we will mainly use "panic" works from the 1960s and 1970s.
\end{abstract}

\section{Résumé}

Dans cet article, nous envisageons d'analyser la présence et l'importance des sexualités non normatives, celles qui échappent à la fonction reproductrice, dans l'œuvre de Fernando Arrabal, auteur espagnol, né à Melilla en 1932, exilé à Paris où il habite depuis 1955 . Le travail est divisé en trois parties et une conclusion: d'abord, nous exposerons le lien existant entre Eros et Thanatos afin d'élucider les relations qui s'établissent entre l'érotisme et la pulsion de mort, entre l'amour et la souffrance dans son œuvre; ensuite, nous aborderons le Désir homosexuel en vue d'exposer les aspects narcissiques et sadomasochistes de cette fascination qui apparaissent dans la création arrabalienne; enfin, dans la troisième partie intitulée Plaisirs phalliques, nous nous centrerons sur certaines pratiques sexuelles telles que la masturbation et la fellation pour montrer la valeur symbolique et "panique" qu'elles acquièrent dans la création de l'auteur. Ainsi, nous constaterons qu'Arrabal, en tant qu'auteur engagé, essaie de se débarrasser de la répression que les régimes autoritaires exercent sur les personnes exprimant une sexualité dissidente. Pour illustrer 


\section{Key-words}

sexuality, dissent, body, commitment, Arrabal. nos propos, nous nous servirons essentiellement des œuvres "paniques" des années 1960 et 1970.

\section{Mots-clés}

sexualité, dissidence, corps, engagement, Arrabal.

\section{Eros y Thanatos}

Gilles Mayné afirma acertadamente que el erotismo nos plantea un desafío ya que su característica principal es la de propulsarnos irresistiblemente fuera del orden tranquilo e inalterable de nuestra realidad cotidiana para mantenernos despiertos a "une expérience d'un autre type, d'une tout autre intensité" (Mayné, 2001: 11).

Sin lugar a dudas, Fernando Arrabal debe a su estricta educación religiosa la indisociable unión entre amor y sufrimiento, entre erotismo y muerte. El dramaturgo confiesa a este respecto que no concibe el amor sin violencia y que ha sentido la intensidad del amor a través del sufrimiento (Schiffres, 1969: 24). De este modo, el amor y la muerte estarán presentes en toda su producción artística.

Intentaremos, en primer lugar, analizar el concepto que el autor tiene del amor y del erotismo. Arrabal parece no hacer una clara distinción entre el erotismo y la pornografía. En este sentido, define el erotismo como pornografía redimida por el amor (Espinasse, 1969: 16-17). Sin embargo, se muestra contrario a la vulgaridad que él considera como algo absolutamente distinto. A su modo de ver, el erotismo y la pornografía pertenecerían a ese mundo maravilloso de nuestra infancia, o a ese otro de nuestros impulsos más mágicos. Se trata de una gran fuerza que forma parte del universo del bien, una de esas energías vitales que un día ganarán el combate a las fuerzas del mal, que no son otras que los sistemas represores, la policía o la guerra. Una de las armas simbólicas de esos enemigos maléficos es precisamente fomentar la confusión entre el erotismo y el libertinaje, lo que conlleva en el fondo el desprecio del amor y de los seres humanos.

La mayor parte de las obras de Arrabal se desarrollan en espacios habitados por las clases más humildes de una sociedad dominada por el dinero en la que no hay cabida para la "perversión". En este contexto mercantil, donde todo se compra y se vende, donde uno vale según lo que posee, las prácticas y los actos sexuales, sean del tipo que sean, no son ni sucios ni bestiales, sino un simple acto de consumo. Y es que, en opinión del autor, asistimos a una desacralización de la pornografía a través del lenguaje, hasta tal punto que los atributos que puede tener una persona se reducen al hecho de ser o no "baisable", o sea consumida como puro objeto sexual.

Arrabal defiende un amor violento y bestial, sucio a la vez que inocente, por eso trata de explorar y actualizar continuamente aquellos momentos de su infancia que representan y 
ejemplifican esta particular visión del amor. No obstante, el escritor se define como alguien muy púdico, especialmente tímido, y prefiere las relaciones monógamas a las polígamas; las primeras le parecen más fascinantes puesto que favorecen la explosión liberadora del erotismo. Por esta razón, podemos constatar que en muchas de sus obras los personajes aparecen a menudo en pareja, desde su extraordinaria y entrañable Fando et Lis perteneciente a su Théâtre I, publicado por Julliard en 1958, tres años después de su llegada a París. En su opinión, hay que ser infeliz para cambiar. En muchos casos se trata de relaciones heterosexuales donde la mujer ocupa un papel esencial en tanto que iniciadora, con una carga más instintiva que el hombre. Por esta razón, la mujer ofrece más posibilidades eróticas que el hombre y estaría en un estado de superioridad en cuanto al universo amoroso y erótico.

Desde un punto de vista más filosófico y contemplativo, con el fin de perfilar su tesis sobre el erotismo y su idea de que los grandes escritores eróticos son aquellos que ignoran el erotismo, Arrabal alude muy a menudo a los grandes místicos que él admira y en especial a Teresa de Ávila, a la que se refiere en estos términos:

Quand elle priait, elle lévitait. Elle disait alors aux sœurs qui l'entouraient: 'Attachez-moi, soutenez-moi pour ne pas léviter'. Elle n'ignorait pas que si elle lévitait, l'Inquisition la brûlerait vive. Cette femme-là, sans savoir qu'elle parlait d'érotisme, a dit des choses merveilleuses. Par exemple, que Dieu plongeait dans ses entrailles une épée de feu qui lui procurait une douleur et une joie infinies. II est difficile de mieux parler d'amour. (Espinasse, 1969: 15)

Como vemos, Arrabal reivindica la reutilización y actualización subversiva de los místicos españoles, aunque es conocedor y seguidor de los postulados que defiende Georges Bataille respecto al erotismo. De hecho, Bataille, en su estudio 5 de L'Érotisme, titulado "Mystique et sensualité", insiste en que su intención no es la simplificación o la banalización en cuanto a la interpretación sexual de la vida mística: "Si, de quelque façon l'effusion mystique est comparable aux mouvements de la volupté physique, c'est une simplification d'affirmer, que les délices dont parlent les contemplatifs impliquent toujours un certain degré d'activité des organes sexuels" (Bataille, 1985: 248). No conviene, sin embargo, descuidar que la experiencia de la contemplación se vinculó muy pronto al despertar más atento referente a las relaciones del gozo espiritual y la emoción de los sentidos.

Aunque parece poco probable que el pasaje, donde Teresa de Ávila evoca el éxtasis místico representado por una lanza que le atraviesa las entrañas, reproduzca un "violento orgasmo" (Bataille, 1985: 249), el escritor y antropólogo parece seducido por el episodio de la lanza, que fascina igualmente a Arrabal, y lo evoca de la siguiente manera:

Je lui vis une longue lance d'or et à sa pointe paraissait être une pointe de feu, il me sembla l'enfoncer en plusieurs reprises dans mon cœur, et percer jusqu'à mes entrailles! Quand il la ressortait, il me semblait les sortir aussi, et me laisser toute en feu du grand amour de Dieu. La douleur était si grande qu'elle me faisait gémir et cependant 
la douceur de cette douleur excessive était telle que je ne pouvais souhaiter en être délivrée... La douleur n'est pas corporelle, mais spirituelle, bien que le corps y ait sa part et même une large part. C'est une caresse d'amour si douce, qui a lieu alors entre l'âme et Dieu, que je prie Dieu dans sa bonté de la faire éprouver à quiconque pourrait croire que je mens. (Bataille, 1985: 248-249)

Ahora bien, como ya hemos anticipado, lo que interesa principalmente a Arrabal es la transgresión de la experiencia mística, dejando en cierto modo de lado un análisis más profundo o transcendental de su dimensión y de su alcance erótico. Se trata de una técnica habitual del autor que consiste en servirse de un motivo conocido o recurrente, pero deformando su mensaje inicial. De este modo tan peculiar, el pasaje aludido de la unión mística entre el alma y Dios adquiere en su emblemática L'Architecte et L'Empereur d'Assyrie ciertas connotaciones burlescas, pues se ha desacralizado completamente su contenido al sustituir las "entrañas" por el "culo". Esta obra aparece dentro del volumen V de su teatro que lleva el título de Théâtre Panique, publicado por Christian Bourgois en 1967.

L'EMPEREUR, aveugle, ton solennel.- [...] O Seigneur, je te contemple avec les yeux de la foi maintenant que mes yeux sont morts. O Seigneur, comme je suis heureux! Je sens, comme Sainte Thérèse d'Avila, que tu m'introduis une épée dans le cul.

L'ARCHITECTE, en langage canin.- Dans les entrailles.

L'EMPEREUR.- C'est ça, dans les entrailles, je sens que tu introduis dans mes entrailles une épée de feu qui me procure une joie et une douleur sublimes. O Seigneur! Je sens aussi, comme la sainte, que les diables jouent à la balle avec mon âme. (Arrabal, 1967: 170)

Vemos pues como el Emperador se entrega a una ceremonia subversiva de la unión mística, blasfematoria y sacrílega, desde el punto de vista religioso, que se acentúa por la alusión a una unión anal con Dios. No obstante, este hecho desorientará aún más al Arquitecto, ya que el premio de la fe ("une épée dans le cul") o el castigo de no tenerla ("des fers rouges dans l'anus") coinciden prácticamente, lo que conlleva, aparte de la continua parodia a la que el autor somete las referencias religiosas, la incomprensión por parte del personaje que se cuestiona la utilidad efectiva de dicha fe.

L'ARCHITECTE.- Tu me baptises?

L'EMPEREUR.-Comment? Tu n'es pas baptisé? Tu cours à ta perdition. Pendant toute l'éternité tu vas rôtir jour et nuit et l'on choisira les plus belles diablesses pour t'exciter, mais elles t'enfonceront des fers rouges dans l'anus.

L'ARCHITECTE.- Tu m'avais dit que j'irais au ciel.

L'EMPEREUR.- Enfant! Comme tu connais mal la vie. (Arrabal, 1967: 96)

Efectivamente, el cuchillo y el puñal, instrumentos sacrificiales asociados con el asesinato y la muerte, pueden considerarse igualmente como símbolos fálicos, de placer y dolor al mismo tiempo. En numerosos ritos iniciáticos, empezando por la circuncisión, el sacerdote 
saca el cuchillo de la vaina, como la verga del circunciso saldrá del prepucio. No cabe la menor duda de que el simbolismo general de los instrumentos cortantes o penetrantes es el principio activo que modifica la materia pasiva. Por esta razón, y de modo frecuente, el cuchillo se asocia simbólicamente a la idea de ejecución, de muerte, de venganza o de sacrificio (Chevalier \& Gheerbrant, 1989: 306).

Numerosos son los ejemplos de esta asociación entre placer y dolor, amor y muerte, en la obra arrabaliana. Al final de La Communion solennelle, perteneciente igualmente al Théâtre Panique, la comulgante, en una suerte de complejo ritual, mata con un puñal al necrófilo, mientras éste está poseyendo sexualmente a la muerta, con lo que su vestido blanco queda manchado de esa sangre impura. Esta ceremonia puede simbolizar igualmente el abandono de su etapa de niña y el paso a la vida de adolescente o de "vraie petite femme", sexualmente activa, con deseos claramente explícitos por la atracción que ejerce el sexo del necrófilo, cada vez más abultado y transformado finalmente en serpiente.

LA FILLETTE.- (Froidement.) Que fait-il avec la morte?

LA GRAND-MÈRE.- II couche avec elle.

La fillette et la grand-mère sortent à gauche.

Au loin se perd la voix de la grand-mère.

VOIX DE LA GRAND-MĖRE.- Aujourd'hui, alors que tu vas recevoir la première communion, tu vas devenir une vraie petite femme. Le Seigneur va descendre dans ton cœur et te purifier de toute faute...

Longue pause.

La lumière baisse.

La fillette habillée en première communion entre en scène avec un couteau. Elle s'approche du cercueil, contemple longuement ce qui s'y passe. Enfin elle donne des coups de couteau à l'intérieur (dans le corps du nécrophile).

Le sang tache sa robe de communiante.

Elle rit.

Des ballons rouges montent du cercueil vers la lune. (Arrabal, 1967: 26-27)

Fernando Cantalapiedra interpreta los globos ascendientes manchados de sangre como parte integrante de una poética del auto sacramental y la elevación característica de la celebración eucarística (Cantalapiedra, 1997: 111). Sin embargo, Arrabal se sirve de sus propios personajes para ofrecernos una exégesis de estos rituales simbólicos que aúnan Eros y Thanatos. Así, en la obra Une tortue nommée Dostoïevsky, que forma parte del volumen VI de su teatro publicado por Christian Bourgois en 1969, será la propia Liska, quien nos facilite, como si de una experta psicoanalista se tratara, la interpretación muy certera y atinada, no exenta de cierto humor negro marcadamente surrealista, de los continuos sueños de clara índole sexual de su neófito marido.

MALIK.- J'ai rêvé que j'étais coiffé de petits poissons allongés comme des anguilles. C'était une sorte de chevelure qui me recouvrait entièrement. Je marchais à ton côté, 
je prenais ta tête et je te faisais une petite blessure au front avec un couteau, et avec l'extrémité du couteau j'extirpais de ta tête un pois chiche qui avait un visage de vieille. Silence. Liska réfléchit.

LISKA.- J'y vois ta nostalgie de paternité: tu rêves toutes les nuits de choses semblables.

MALIK.- Où vois-tu cela?

LISKA.- Ta tête... les anguilles, tu es la méduse. Cela veut sûrement dire que tu disposes d'innombrables sexes qui surgissent de ta tête, de ton intelligence (nous sommes à l'ère de la connaissance). D'ailleurs, pour entrer en contact avec moi, comme si ça ne suffisait pas, tu te sers d'une autre image phallique, le couteau, et avec lui tu extrais de ma tête le fils que tu désires avoir. (Arrabal, 1969: 153-154)

La unión entre amor y sufrimiento, a través de toda una simbología ligada a los objetos punzantes, aparece también magistralmente ilustrada en Ars Amandi, obra incluida en el Théâtre VIII, publicado por Christian Bourgois en 1970. En ella, Bana y Ang suplican a Lys, con unas imploraciones llenas de belleza poética, que, para probarles su amor, clave un puñal de larga hoja en sus respectivas frentes; acción que ansiosamente esperan arrodillados y con los ojos cerrados. Antes de prestarse a este ceremonial, Lys necesita excitar su deseo por medio de la contemplación de fotos de burdeles.

BANA.- Nous serons tes hérissons apprivoisés... nous serons tes singes savants... mais ne nous méprise pas. Aime-nous.

ANG.- Montre-nous que malgré tout nous ne te sommes pas indifférents.

LYS.-- Mais que vous êtes sots... Ne faites pas l'enfant. Bien sûr que je vous aime.

BANA.- Nous t'achèterons tout ce dont tu auras besoin, nous t'apporterons nos rêves pour que tu joues aux cartes avec eux, mais... perce nos fronts d'un coup de poignard pour prouver que tu nous aimes.

ANG.- Oui, transperce nos fronts, si nous en sommes dignes.

Ils sortent deux couteaux à large lame.

Ils s'agenouillent et ferment les yeux en attendant que Lys plonge le poignard dans leur front.

BANA.- Même si ce n'est qu'un petit peu: plonge le poignard, de grâce.

ANG.- Oui, oui.

LYS.- Auparavant, projetez-moi des photos de bordels.

Ils se redressent aussitôt et projettent sur le mur des gravures fin de siècle qui représentent les minois coquins des jeunes putains de l'époque. (Arrabal, 1970: 37-38)

Podemos constatar la complejidad de las relaciones amorosas en el universo arrabaliano. Este hecho pone de manifiesto una sexualidad que deja entrever las estrechas relaciones que se establecen en la psique de los personajes entre erotismo y pulsión de muerte, entre placer y dolor. Tanto en Ars Amandi, La Communion solennelle o L'Architecte et L'Empereur d'Assyrie, entre muchos otros ejemplos, esta unión se integra dentro de un ceremonial sacrificial que posee una fuerte simbología sexual.

La muerte ligada al amor representa sentimientos ambivalentes de devoción y de odio 
y pone de relieve una relación con una clara tendencia incestuosa entre la madre y el hijo. No cabe la menor duda de que sobre toda la obra de Arrabal planea la sombra del recuerdo de esas relaciones ambiguas que siempre mantuvo con su madre, adorada y odiada al mismo tiempo y secretamente acusada de haber entregado a su padre a las autoridades franquistas y, posteriormente, haber usurpado su autoridad. Como afirma el Emperador-esposa: "il la haïssait mortellement et il l'aimait comme un ange, il ne vivait que pour elle. Pour un homme de son âge, croyez-vous que ce soit normal d'être jour et nuit pendu à ses jupons? Il n'avait pas besoin d'une femme mais d'une mère" (Arrabal, 1967: 151).

\section{EI deseo homosexual}

Las formas del amor consideradas como marginales y disidentes o, dicho de otro modo, las distintas identidades u orientaciones sexuales parecen fascinar a Arrabal estimulando su imaginación. En este sentido, la pulsión o el deseo homosexual, y todos los fantasmas asociados, está muy presente en su obra. El autor siempre ha mostrado un interés particular por esas prácticas y manifestaciones de la sexualidad condenadas por la religión y los dogmas de la sociedad biempensante, al menos en el ámbito público. Es el caso de la obra Le Jardin des délices, que forma parte del Théâtre VI (1969) y que trata del amor entre dos mujeres, o de L'Architecte et l'Empereur d'Assyrie, obra poliédrica y compleja como estamos viendo, que podría interpretarse como un tratado de la frágil frontera entre la amistad y el amor entre dos hombres.

Existe en Arrabal una voluntad manifiesta de mostrar lo sexual que se concretiza de manera performativa, teatral. Este era uno de los aspectos que más le impresionaba de los pintores surrealistas. Como muy acertadamente señala Francisco Torres Monreal, se podría establecer un paralelismo entre Fernando Arrabal y Jean Genet, en lo referente a la expresión de la sexualidad, en un contexto de represión social y moral. En este sentido, ambos autores compartirían un fascinante universo creativo que hace visibles, cada uno a partir de sus vivencias particulares, el deseo, la transgresión, el crimen y la muerte.

Para Arrabal, todas las formas y manifestaciones de la sexualidad son propias del ser humano, considerado esencialmente como ser "deseante". El inconsciente "hiperbolizará notablemente las imágenes sexuales evidenciadas en ocasiones en las llamadas desviaciones (necrofilia, bestialidad, homosexualidad...)" (Torres Monreal, 1986: 44), pero su interés radica esencialmente en la "imbricación de lo sexual con lo sagrado" (Ibid.). Lo sacrílego arrabaliano "no consistirá en el hecho de haber desacralizado lo sagrado al erotizarlo, sino más bien en haber sacralizado el sexo. Pero ¿hay en ello sacrilegio?” (Ibid.).

En las entrevistas que concedió a Albert Chesnau y Ángel Berenguer, el propio autor argumenta las razones de la atracción que le produce la homosexualidad. Afirma que los homosexuales ejercen sobre él la misma fascinación que experimenta frente a cualquier mi- 
noría perseguida. Recuerda igualmente que, en la España franquista, la homosexualidad era el "Mal" (Chesnau \& Berenguer, 1978: 117), como el comunismo o la masonería. Reconoce que el deseo homosexual supone una gran tentación para él, aunque se posiciona diciendo que dicha atracción se ha quedado únicamente en seducción, al menos en aquella época de finales de los años 70 del siglo pasado, y en lo que a su vida personal se refiere.

No entraremos aquí en valorar los prejuicios que pueda tener el propio autor al comparar la homosexualidad con la droga o el juego, pero sí que es oportuno constatar que parece que Arrabal necesite sublimar esos deseos acallados a través de sus personajes. Cabría, además, afirmar que existe en esta actitud una clara tendencia represora o inhibidora que encuentra su liberación al decir lo que no se ha podido verbalizar durante años y al expresar lo que no se ha podido hacer, y se querría llevar a cabo: "Ne sommes-nous tous des refoulés optimistes ou pessimistes?" (Espinasse, 1967: 16), añade Arrabal en otra entrevista a Françoise Espinasse.

Queremos creer al autor cuando sostiene una postura disidente y afirma que no busca en esos temas más que el estimulante o el acicate de la vida, y la dicha de vivir lejos de cualquier norma social y moral. Es evidente que el artista busca su propia vía, de manera más o menos acertada según se mire, para liberarse del peso de una sociedad demasiado represora. Al verbalizar este sufrimiento y hacer visibles todas sus obsesiones, Arrabal se enfrenta honestamente a ellas, lo que consideramos un signo de valentía en la sociedad y la época franquista a la que hace referencia continuamente su obra, a pesar de que se fue a Francia muy joven y tuvo ocasión de conocer todas las revoluciones sociales y sexuales de colectivos disidentes de los años 60 y 70 del siglo pasado.

De este modo, la bisexualidad y la homosexualidad, tanto masculina como femenina, se muestra a menudo en la obra arrabaliana. En L'Architecte et L'Empereur d'Assyrie se alude a ella de una manera más o menos velada, pero al mismo tiempo de un modo inocente y natural. En dicha obra, los dos personajes masculinos se prestan a un continuo juego de roles y travestismos. Es curioso destacar que, antes de llegar a la isla, el Emperador estaba casado sin hijos y que su vida marital no era precisamente satisfactoria, incluso pegaba a su mujer que lo engañaba con otros hombres. Una esposa que confiesa que uno de sus deseos ocultos es haber tenido un harén de mujeres que se ocupara de ella.

L'EMPEREUR, épouse.- Il ne me battait même plus.

L'ARCHITECTE.- Il fut un temps où il vous battait?

L'EMPEREUR, épouse.- Oui. Pour affirmer sa virilité. Pour se venger des innombrables humiliations qu'il subissait. Après il n'en a même pas eu le temps tant il revenait fatigué de son bureau. [...]

L'ARCHITECTE.- L'avez-vous trompé avec d'autres hommes ?

L'EMPEREUR, épouse.- Et que vouliez-vous que je fasse toute la journée seule?

L'attendre? [...]

L'ARCHITECTE.- Quel aurait été votre secret désir?

L'EMPEREUR, épouse.- Jouer du luth en costume d'époque tandis qu'un chevalier 
du genre Machiavel m'aurait caressé, peut-être baiserait-il mon dos nu que laisserait voir la grande échancrure de mon corsage. J'aurais aimé aussi, bien que je n'aie aucune inclination pour le saphisme, disposer d'un harem de femmes qui prendrait soin de moi (Arrabal, 1967: 149-150).

El Emperador no sólo sueña con un mundo ideal, sin guerras ni religiones ni proselitismo, donde sólo hubiera mujeres lesbianas afirmando: “Une fille. Il n’y a plus que des filles. Une humanité entière de lesbiennes. Finis les guerres, les religions, le prosélytisme, les accidents de voiture. L'humanité heureuse. Le meilleur des mondes. On ne dépensera plus son argent qu'en godemichés" (Arrabal, 1967: 136). Desvela, además, que su madre mantenía relaciones con su mejor amiga, Olympia de Kant, durante su época de estudio en el instituto, lo que conllevaría que las expulsaran a las dos, debido a las costumbres conservadoras que imperaban en ese momento.

L'ARCHITECTE.- Avez-vous connu la mère de l'accusé?

L'EMPEREUR.- Comment ne pas la connaître? C'était ma meilleure amie. Nous étions des amies d'enfance: on nous avait renvoyées du même lycée...

L'ARCHITECTE.- Comment vous a-t-on renvoyées?

L'EMPEREUR, Olympia.- Des histoires de gamines. Nous jouions au médecin toutes nues, à nous prendre la température, à nous faire toutes sortes d'opérations, à renverser sur nos têtes des encriers et l'encre coulait, lentement, jusqu'aux pieds... A cette époque de coutumes vieillottes, allez savoir ce qu'ils se sont imaginé. Bien sûr nous nous embrassions, comment ne nous serions-nous pas embrassées? Nous étions deux fillettes qui naissent à la vie. Toujours est-il qu'on nous a chassées du lycée. (Arrabal, 1967: 172)

No será la única vez que El Emperador aluda, de manera más o menos cómica, a las relaciones homosexuales en la escuela. Tras ponerse a cuatro patas, convertido en elefante sagrado rosa, montado por el Arquitecto que le ha puesto previamente una cadena por la trompa para hacer que avance, finge mantener una conversación telefónica con otro "Presidente", que está a punto de hacerle una declaración de guerra en estos términos: "Une déclaration. Président, nous ne sommes plus à l'école. Un temps. Ne le prenez pas sur ce ton, je ne savais pas que vous étiez homosexuel. Me faire une déclaration à moi. Vieux paillard, petit coquin! (Arrabal, 1967: 109).

También hay un momento en el que el Arquitecto se convierte en el perro del Emperador, dado que este último expresa las inclinaciones zoófilas que perviven en él, asociadas a un deseo y un ritual de sumisión, homosexual en este caso, que incluye objetos altamente erotizados, como la correa o la capucha.

L'EMPEREUR.- Si tu veux savoir la vérité, je n'aimais qu'un seul être: mon chienloup. II venait me chercher tous les jours. Nous nous promenions ensemble, comme deux amoureux: Pégase et Pâris. Je n'avais pas besoin de réveil: c'était lui qui tous les matins accourait me lécher les mains [...]. 
Anales de Filología Francesa, n. ${ }^{\circ}$ 28, 2020

Sexualidad y disidencia en la obra de Fernando Arrabal

L'Architecte se met à quatre pattes, se passe une laisse autour du cou, et se coiffe d'une cagoule.

L'ARCHITECTE.- Je suis ton chien-loup des îles.

L'EMPEREUR.- Eh! Médor! Va chercher, va chercher! [...] Voyons ce que va découvrir mon bon chien fidèle. [...]

L'Empereur le flatte de la main avec tendresse et lui donne de petites tapes sur l'échine. "Dans l'échelle des créatures il n'y a que l'homme pour inspirer un dégoût soutenu, la répugnance que fait naître une bête est passagère".

Le chien-architecte approuve, heureux, et aboie joyeusement.

Celui-là était vraiment des miens. C'est ça, reste à mes côtés pour toujours comme un chien et je t'aimerai toute l'éternité, ensemble comme le chien Cerbère et Homère nous parcourrons les royaumes abyssaux de l'Océan! (Arrabal, 1967: 168-170)

Fernando Arrabal aparece con una entrada en la Encyclopédie du sadomasochisme para aludir a obras tempranas como Oraison, Les Deux Bourreaux o Le Cimetière des Voitures, pertenecientes al Théâtre I (1958). En ellas, el autor “développe un 'cérémonial panique' que personnages et spectateurs appréhendent à travers un lien de nature sadomasochiste" (Lamare, 2000: 21). De este modo, pone de manifiesto las prácticas de dominación como una variante de las relaciones de poder, por lo general afectivas o eróticas, que se establecen entre los personajes.

Carlos Castilla del Pino, en su ensayo Introducción al masoquismo (1973), presenta una serie de teorías que pueden ayudarnos a dilucidar el origen y la causa de esta conducta en los personajes arrabalianos. Según sus postulados, existe en cualquier individuo "normal" una conducta masoquista y hay componentes masoquistas en una conducta "normal" (erótica o no). El hecho de calificar tales connotaciones como "perversas" implica la introducción de un juicio de valor normalmente negativo, es decir como una consecuencia directa de una conducta patológica aberrante.

La paradoja y la contradicción no caracterizan en absoluto lo que se podría considerar “patológico". La envidia, los celos, las actitudes ambivalentes, la perplejidad y la indecisión, la inhibición, los componentes fetichistas, voyeristas, sadomasoquistas, las interpretaciones paranoicas e incluso los fenómenos pseudoperceptivos son formas de conducta que coexisten con un funcionamiento "normal" del sujeto. En ningún caso pueden emplearse para calificarlo. La relación paradójica de objeto que el masoquista establece con su pareja es la expresión de su contradicción intima, el resultado de la heterogeneidad de su persona. Es esta relación de objeto la que hace posible una forma de comunicación interpersonal gratificante a través del dolor o del sufrimiento en su acepción más amplia.

No debemos olvidar que el sadomasoquismo obedece a un rito muy específico cuya característica primordial es la constancia y la reiteración. En este rito humillante, que en Arrabal adquiere normalmente tintes de juego infantil, uno de los participantes adopta frecuentemente el papel de esclavo y se degrada, según sus fantasías, al nivel de un animal que se mueve a cuatro patas (perro, caballo, vaca o elefante), deseando que lo traten como tal y 
adoptando posturas semejantes a éste. Deseará pues que lo monten, que cabalguen sobre él, que lo espoleen, que lo aten o que le peguen.

\author{
L'EMPEREUR.- [...] A cheval! \\ L'ARCHITECTE.- Je fais le cheval? \\ L'EMPEREUR.- Non, ce sera moi! \\ L'Empereur se met à quatre pattes. \\ L'Architecte l'enfourche comme une monture. \\ Dis-moi hue! \\ L'ARCHITECTE.- Hue dada! \\ L'EMPEREUR.- Fouette-moi avec la cravache! \\ L'Architecte le fustige avec une branche. (Arrabal, 1967: 83-84)
}

Además, para dar visibilidad a todo este universo de relaciones de sumisión y dominación que se establecen entre los personajes, Arrabal se sirve de diferentes objetos simbólicos como las cadenas, los látigos, las fustas u otros objetos de uso similar como una rama. Se trata de atributos que acompañan al personaje que desempeña el rol de "dominador" en ese momento, ya sea físico o moral.

L'ARCHITECTE, il apporte un fouet.- Tu me bats?

L'EMPEREUR, condescendant.- C'est bon. Quel rôle dois-je jouer? [...]

L'ARCHITECTE.-Allons, vite[s], bats-moi, je n'y tiens plus.

Il a le dos nu et attend de recevoir des coups de fouet. [...]

L'EMPEREUR.- Où faut-il fustiger Monsieur?

Avec emphase:

Sur ses fesses roses, sur son dos d'ébène, sur ses cuisses, colonnes élégiaques de l'immortelle Sparte?

L'ARCHITECTE.- Bats-moi, bats-moi!

L'EMPEREUR.- C'est bon, j'y vais. (Arrabal, 1967: 97-98)

No obstante, no podemos concluir que estas conductas, pertenecientes a un claro ritual sadomasoquista, sean de índole puramente erótica pues el carácter infantil y la dimensión moral, pertenecientes a una esfera en la que los factores culturales tienen un peso considerable, están muy presentes.

A esta presencia de rituales de dominación y sumisión, propios de un deseo homosexual latente, se unirá una visión del incesto llena de prejuicios sociales que se concreta en las relaciones entre hermanos en la época de la adolescencia, etapa esencial de explosión de la sexualidad en la obra arrabaliana. En una escena especialmente intensa en la que el Emperador se quita la máscara y se resiste a seguir con el juego de roles, descubrimos que éste violaba a su hermano y lo obligaba a violarlo. Los términos de "perversión", "violación" y "obligación" denotan claramente una degradación moral, aunque el juicio que encubren queda en cierto modo ridiculizado. 
L'ARCHITECTE.- Témoin vous disiez que vous alliez nous raconter ce que votre frère faisait avec vous.

L'EMPEREUR, frère.- Mon frère, le po-è-te s'amusait, alors que je n'avais que dix ans et lui quinze à me pervertir, à me violer et à m'obliger à le violer

L'EMPEREUR, arrachant son masque.-C'étaient des jeux d'enfants sans grande importance.

L'ARCHITECTE.- Silence. Que le témoin poursuive son récit. [...]

L'EMPEREUR, frère.- Il attendait le départ de notre mère. Nous restions seuls à la maison, il remplissait la moitié de la baignoire d'huile d'olive et le divertissement commençait. Ensuite venait le plus drôle. Lorsque tout était terminé, il se mettait à trembler et à se donner des coups contre la baignoire. Je me souviens qu'un jour il a fini par s'entailler largement la main et il a aspergé son sexe avec son sang en fredonnant un cantique et en sanglotant. (Arrabal, 1967: 157-158)

A veces, este deseo velado y violento, reprobable socialmente, aparece unido a ciertas pulsiones narcisistas que evidencian de nuevo toda una serie de estereotipos y clichés en torno a la homosexualidad, entendida de manera simplista como un ansia de encontrar un doble o reflejo de sí mismo. Esta idea reductora y deformada se pone de manifiesto cuando el Emperador, abandonado por el Arquitecto, da rienda suelta a toda una retahíla de declaraciones amorosas hacia un espantapájaros que él mismo ha vestido con sus propias ropas: "Empereur je suis amoureux de vous. Vous êtes le plus beau, le plus séduisant des hommes. Pour un mot de vos lèvres..." (Arrabal, 1967: 132).

Sin embargo, el amor más "puro" prevalece sobre estas imágenes manidas de la homosexualidad, ya sea "perversa" o "morbosa", ya sea "infantil” o "narcisista”, situándose por encima del juego y de la farsa, y adquiere en numerosos pasajes un carácter tierno e ingenuo, realmente poético.

Así, el Arquitecto declarará en varias ocasiones su amor sincero al Emperador que, muy emocionado y a punto de llorar, piensa que se está riendo de él, cosa que el Arquitecto desmiente: "Moi... Sincèrement: Je t'aime..." (Arrabal, 1967: 111). No sólo palabras sino gestos cotidianos que inciden en la misma dirección de afecto sincero y complicidad entre ambos: 'La nuit c'est toujours la même chose: 'gratte-moi un peu jusqu'à [ce] que je m'endorme.' Aussitôt tu te mets à ronfler comme un soufflet de forge, mais dès que je cesse de te gratter, silence, tu ouvres un œil, et tu déclares: 'gratte-moi, je ne dors pas encore"' (Arrabal, 1967: 161).

Uno de los episodios más emotivos de la obra es cuando el Emperador, tras escuchar la declaración de amor del Arquitecto, le da un beso y expresa su deseo de ser devorado por su compañero, en una fusión total a través del canibalismo.

L'ARCHITECTE.- [...] Empereur tu sais que je t'aime.

L'EMPEREUR, ému.- Tu le dis sérieusement.

L'ARCHITECTE.- Oui, très sérieusement. [...] Tu m'embrasses?

L'Architecte ferme les yeux. 
L'Empereur s'approche de lui et l'embrasse très cérémonieusement sur le front.

Sur le front?

L'EMPEREUR.- Je te respecte, moi, que sais-tu de ces choses?

L'ARCHITECTE.- Apprends-les-moi comme tout ce que tu m'as enseigné.

L'EMPEREUR.- [...] Je désire que... je désire... enfin... que tu me manges... que tu me manges. Je veux que tu sois à la fois toi et moi. Tu me mangeras entièrement, $\mathrm{Ar}$ chitecte, tu m'entends? (Arrabal, 1967: 184-185)

Constatamos pues que los dos personajes se aman profundamente, pero es esencialmente a raíz del abandono del Arquitecto cuando el Emperador se da cuenta de que no puede vivir sin él. La soledad se convierte en un fardo insoportable. Ambos se necesitan. La transformación simbólica del Arquitecto en Emperador se anuncia desde el final del primer acto. De este modo, las palabras del Emperador se tornan en un bello canto de la ausencia del ser amado, casi una elegía.

L'EMPEREUR.- [...] Architecte, reviens! Cesse de ramer. C'est mauvais pour les poumons. Tu auras de l'asthme. [...] Architecte, viens! Nous serons amis. Nous construirons ensemble une maison. Nous ferons s'élever des palais avec des labyrinthes, nous creuserons des piscines dans lesquelles viendront se baigner les tortues de mer, je te donnerai une automobile pour que tu puisses parcourir toutes mes pensées... Très triste. Et des pipes d'où jaillira de la fumée liquide dont les volutes se changeront en réveillematin, j'assécherai les marais pour qu'émerge de leur fange une nuée de flamants roses aux couronnes de papier d'argent, j'assaisonnerai les mets les plus délicieux et tu boiras des liqueurs distillées avec l'essence de mes rêves... Architecte! Il crie: Architecte!... Pleurant à demi: Nous serons heureux! (Arrabal, 1967: 141-143)

\section{Placeres fálicos}

En esta presencia del homoerotismo en su sentido más amplio y complejo, el falo ocupa un lugar preponderante, visión sesgada y reductora sin lugar a dudas, pero denunciadora al mismo tiempo de las convenciones sociales. Tratándose de dos personajes masculinos abandonados a su suerte en una isla desierta, la alusión a una sexualidad muy centrada en los genitales no podía obviarse.

Preguntado Arrabal sobre qué lugar ocupaba la sexualidad en ese clima de represión política, intelectual y moral de su infancia, el autor responde: “Je n'y pensais pas, ou plutôt je ne pouvais pas y penser, mais elle m'échappait pour cette raison et m'éclaboussait entièrement comme de la mousse sous pression. [...] Mon éducation sexuelle fut totalement autodidacte et intériorisée. Je ne pouvais connaître que mon corps" (Schiffres, 1969: 24-26).

Como precisa de manera excelente James Hillman, en el capítulo VII titulado "Pan et la masturbation" de su ensayo Pan et le cauchemar ${ }^{1}$, ésta es la práctica sexual de más larga

1 Traducción francesa de 1979 del original americano de 1972 (Pan and the Nightmare, Spring Publications), por Thierry Auzas y Marie-Jeanne Benmussa en colaboración con Monique Salzmann. 
duración en la vida del ser humano. Se practica paralelamente a otras actividades sexuales sin que sea un sustituto de éstas, se descubre de modo espontáneo y es la única práctica sexual que se puede practicar en solitario. Arrabal, como autor "pánico", vincula claramente en su obra la masturbación al dios Pan, mitad hombre, mitad macho cabrío, un sátiro de los bosques con una sexualidad desbordada. De este modo, se pone de manifiesto de manera sencilla la necesidad sexual apremiante que se puede apoderar de las personas en su soledad (en particular cazadores, pastores o guerreros) y especialmente en las horas centrales del día, cuando se abandonan a la siesta y se producen erecciones relacionadas con el sueño. Sin embargo, es necesario ir más allá en esta interpretación reductora, ya que esta asociación entre Pan y la masturbación no es sólo apropiada psicológicamente sino necesaria: "car la masturbation fournit un paradigme pour ce type d'expériences que nous appelons instinctuelles, où compulsion et inhibition sont liées" (Hillman, 1979: 68).

A partir de El Arquitecto y el Emperador de Asiria, el autor hará numerosas referencias explícitas a esta práctica. La masturbación formará pues parte de la vida de los personajes de manera natural. Después de ponerse a cuatro patas y empezar a mugir como una vaca, El Arquitecto le pide al Emperador que lo masturbe:

\author{
L'ARCHITECTE.- Meuh! Meuh! \\ Il se met à quatre pattes. \\ Tu vois je suis une vache. \\ L'EMPEREUR.- Tais-toi, fou que tu es. \\ L'ARCHITECTE.- Tu me masturbes?
}

Del mismo modo que el Emperador no vacila en reclamar los besos del Arquitecto, tampoco duda en incluir la masturbación como una de sus imposiciones tras la siesta, como una actividad cotidiana más, durante el lapso de tiempo en el que éste lo abandona:

\footnotetext{
L'EMPEREUR.- [...] Architecte! Architecte! Viens, ne me laisse pas seul. Je suis trop seul. Architecte! Archi...

Il se ressaisit.

Il faudra que je m'organise. Pas de négligence. Réveil à neuf heures du matin. Un brin de toilette. Méditation. Penser à la quadrature du cercle, peut-être écrire des sonnets. Et la matinée passera sans que je m'en aperçoive. A une heure déjeuner, ablutions, puis un peu de sieste, se branler une fois, une seule mais bien, que ça dure trois quarts d'heure, quel dommage de ne pas avoir Histoire d'O sous la main. (Arrabal, 1967: 118-119)
}

Siguiendo a Hillman, vemos que la masturbación reúne los dos polos o aspectos del espectro instintivo, puesto que junto a la pulsión se sitúa la conciencia moral y la fantasía que hacen que la pulsión se acalle o se desvíe. Durante mucho tiempo, se ha asociado o confundido la vergüenza que este acto genera con la prohibición social que se manifiesta por una suerte de autoridad interiorizada. De ahí que se haya juzgado como una actividad nociva "parce 
qu'elle ne sert aucune fin observable" (Hillman, 1979: 69). Biológicamente, no sirve para procrear, por lo que ha sido considerada como una práctica contra natura; emocionalmente, no favorece la relación, por lo que debe ser autoerótica y sin amor; y socialmente, no orienta la libido hacia el nexo social, por lo que resulta anómica, esquizoide e incluso suicidiaria. La masturbación considerada únicamente desde el punto de vista de la civilización sólo puede engendrar su inhibición y los sentimientos asociados de culpa y conflicto psicológico que crea esta conciencia social y moral.

En el punto de vista opuesto, se intenta liberar la masturbación de su prohibición restrictiva dejando que aflore un Pan romántico, caracterizado por el placer desatado que despreciaría el factor moral de la inhibición, complemento de la compulsión que caracteriza al instinto. Esta práctica liberada y liberadora de la masturbación, carente del sentimiento de vergüenza o de conflicto, si bien denota la superación de las restricciones morales, sólo tendría valor fisiológico, sería un mecanismo de relajación y de búsqueda del placer innato, desprovisto de significación para el alma.

Para que la masturbación sea realmente "pánica”, tiene que darse esa compleja unión entre inhibición y compulsión: o bien nos detenemos horrorizados por la masturbación, cubiertos de vergüenza y de imágenes pavorosas, o bien pasamos del miedo a la osadía excitando nuestros órganos genitales. Así, la masturbación calmaría la ansiedad y la suscitaría a otro nivel. Por eso, la sexualidad en su dimensión "pánica”, aquella que expulsa el miedo, nunca se expresará a través del coito, o sea de la unión, sino de la masturbación.

\begin{abstract}
Parce qu'elle est la seule activité sexuelle pratiquée sans partenaire, nous ne pouvons la juger uniquement en fonction de son utilité pour l'espèce ou pour la société. Au lieu de polariser sur son rôle inutile dans la civilisation et dans la procréation, nous pourrions réfléchir sur le service qu'elle peut rendre à la culture et à la créativité intérieures. En rendant plus intense notre intériorité grâce au plaisir, au conflit et à la honte, et en stimulant l'imagination, la masturbation, inutile à l'espèce ou à la société, donne cependant une jouissance génitale, de la fantaisie, et de la culpabilité à l'individu en tant que sujet psychique. Elle sexualise l'imagination, donne du corps à l'esprit, intensifie le vécu de la conscience morale et confirme la puissante réalité de la psyché introvertie. (Hillman, 1979: 73)
\end{abstract}

La masturbación, entendida en este sentido ambivalente y contradictorio, aparece de manera muy temprana en la obra arrabaliana. En La Pierre de la Folie, relato poético en el que Arrabal reúne todos los sueños, o más bien pesadillas, que tenía por aquel entonces, se pone de manifiesto la difícil relación que mantiene el protagonista con su cuerpo y sus complejos infantiles. La masturbación está presente desde el despertar más temprano de la sexualidad, unida a una mezcla de odio y placer voyerista, frente a los demás camaradas de clase que desprecian al protagonista. La búsqueda del placer solitario se mezcla aquí con la repulsión hacia su propio cuerpo y el dolor que le produce la constatación de su diferencia. 
De este modo, su propia sexualidad será mal vivida por el adolescente al vincular su deseo a la monstruosidad.

\begin{abstract}
JE sortais de l'école en courant pour décourager mes poursuivants.
Dès mon retour à la maison je me réfugiais dans ma chambre. A travers les rideaux je regardais mes petits camarades qui scandaient "grosse tête, grosse-tête" ou "Quasimodo, Quasi-modo".

Alors je me déshabillais complètement, je m'examinais dans la glace de l'armoire, et je voyais qu'en effet, ma tête était très grosse, et que je ressemblais à Quasimodo. Je me mettais à pleurer. Les enfants criaient de plus en plus fort "grosse-tête" et "Quasimodo". Et je continuais à m'examiner, nu, dans la glace -en pleurant. Enfin, je me masturbais. (Arrabal, 1963: 111)
\end{abstract}

La masturbación bucal o felación es otra práctica condenada por la moral judeocristiana que aparece en obras de Arrabal. Franck Évrard nos recuerda la ambigüedad esencial de la felación y que la boca es también el lugar del discurso, por lo que esta práctica sexual establece complejos vínculos entre la boca, la palabra y el sexo.

\begin{abstract}
Il ne faut pas renoncer trop vite à percer le mystère de la fellation, son ambiguïté essentielle qui la fait hésiter entre métaphore et métonymie, entre rituel sacré et pratique profane, entre la crudité lexicale transgressive de la "pipe", la précision technique du discours de la sexologie qui parle de "fellation" et la préciosité rhétorique qui nourrit les métaphores sexuelles. Il ne faut pas renoncer non plus à comprendre les liens complexes qu'elle tresse dans les textes littéraires entre la bouche, la parole et le sexe. Loin d'être une catégorie extérieure à l'œuvre, la fellation offre peut-être la possibilité de mettre en valeur et de révéler l'imaginaire, la vision du monde et les stratégies d'écriture d'un écrivain. (Évrard, 2001: 19-20)
\end{abstract}

La felación está presente en obras como ... Et ils passèrent des menottes aux fleurs, que forma parte del Théâtre VII publicado en 1969, o Jeunes barbares d'aujourd'hui, que forma parte del Théâtre X publicado en 1976, siempre por el editor parisino Christian Bourgois. En L'Architecte et l'Empereur d'Assyrie, aparece primeramente ligada al aprendizaje de la lengua, a la crudeza léxica transgresiva no exenta de humor, con este valor ambiguo, al que hemos aludido, en el que el sexo está ligado a la palabra.

L'EMPEREUR.- Comment avons-nous tiré au sort? Avec quoi?

L'ARCHITECTE.- Avec des pipes.

L'Empereur a le fou rire tandis qu'il répète "des pipes, des pipes".

Pourquoi ris-tu Maître?

L'EMPEREUR.- [...] Je ne t'ai jamais dit ce que signifie le mot pipe, faire une pipe. (Arrabal, 1967: 83).

Por otra parte, aviva la imaginación del autor e ilustra los fantasmas de carácter incestuoso, presentes en el pensamiento del Emperador, cuyo origen se remonta al teatro griego 
antiguo y que caracterizan lo que comúnmente se denomina drama edípico. En este sentido, encontramos en la obra una evocación de una posible felación efectuada por la boca materna. Se trataría, como ocurre a menudo en la obra arrabaliana, de un sucedáneo o un sustituto del coito imposible cuyo fin último es la posesión de la madre, que se ha apoderado de forma obsesiva de su mente.

L'EMPEREUR, épouse: [...] Peu avant la disparition de celle-ci, ils traversaient une époque de haine féroce, alors sa mère a sollicité une entrevue que mon mari a acceptée à condition, premièrement que sa mère lui donne pour chaque minute d'entretien accordée une somme très élevée, deuxièmement qu'elle le masturbe avec "sa bouche maternelle", disait-il, afin qu'elle commette le plus infâme des péchés. C'est ce qu'il racontait, il a toujours été si innocent. (Arrabal, 1967: 165)

No obstante, el Emperador, que representa a la sociedad de la que él formaba parte, no puede desprenderse de golpe de todos los prejuicios que ésta tiene en torno a la sexualidad. La presencia de los placeres fálicos, reales o imaginados, no hace más que traicionar la soledad y el profundo desamparo del ser humano que se siente abandonado por Dios y el resto de la humanidad. Por esta razón, la sexualidad del Emperador será problemática y además se verá sometida a un juicio moral, ya que se debate continuamente entre sus apremiantes deseos sexuales y sus servidumbres, potenciados por una feroz represión religiosa. A pesar de ello, será incapaz de privarse de estas prácticas sexuales disidentes.

De este modo, la religión, concretamente la católica, tal como el autor la conoció en su infancia, se convierte en castradora del deseo y hace que el hombre y la mujer se avergüencen de su cuerpo y de la sexualidad como fuente de placer, como muestra este pasaje de La Pierre de la Folie:

LE curé est venu voir ma mère et lui a dit que j’étais "obsédé".

Alors ma mère m'a attaché aux barreaux du lit. Le curé avec un bistouri m'a coupé les testicules et à leur place il m'a mis deux pierres.

Puis ils m'ont porté, pieds et poings liés, jusqu'à l'église des dévôts. (Arrabal, 1963: 99)

Ante el cadáver del Emperador, que yace encima de una mesa, El Arquitecto va adquiriendo la voz, el tono, los rasgos y las expresiones del Emperador, mientras empieza a trocear un pie con un cuchillo y un tenedor, dando inicio al ritual caníbal de transformación.

L'ARCHITECTE.- [...] J'espère qu'aujourd'hui ce n'est pas maigre. Sommes-nous vendredi? Je crois que non. De toute manière, quelle est donc la religion qui défend de manger de la viande le vendredi? Ce salaud d'Empereur, oh! pardon, ne me l'a même pas dit. Dans l'une il y a cette histoire de vendredi, et celles des... croisades. Tiens, je ne me souviens de rien. Dans une autre des harems? C'est un beau fouillis dans ma tête. Si j'ai bonne mémoire, toutes interdisent la masturbation... à moins que... Où sont 
donc ces maudits livres de piété? Au fait, quelle est ma religion? Enfin il faut mieux que je laisse ça de côté. (Arrabal, 1967: 188)

Por tanto, la masturbación, como práctica sexual disidente en el universo arrabaliano regido por el dios Pan, debería ser entendida según sus propios términos, sin ser condenada ni como comportamiento sustitutivo para personas aisladas, ni como comportamiento regresivo para adolescentes, ni como reaparición de fijaciones edípicas, ni como compulsión fisiológica desprovista de sentido que tenga que ser inhibida por esas prohibiciones inversas que son las relaciones personales, la religión y la sociedad. Además, la masturbación es el único acto que nos permite tomar conciencia de nosotros mismos, lo que Hillman denomina "la conscience de soi" (Hillman, 1979: 73).

\section{Conclusiones}

Para concluir, diremos que la obra de Fernando Arrabal, a pesar de ciertas limitaciones o prejuicios de los que es muy difícil desprenderse, posee un carácter altamente social y reivindicativo a la vez. Como él mismo precisa, en el tono irónico que lo caracteriza, antes de llegar a Francia, vivía en una época en que "a Caperucita Roja se le llamaba Caperucita encarnada para evitar malentendidos; la montaña rusa recibía el nombre de montaña suiza. Eso por no hablar de represión sexual que apenas si está esbozada en mis obras. Tenía que haber ido más allá” (Isasi Ángulo, 1974: 232).

Como afirma Ante Glibota, la crítica se ha confundido y ha estado dando vueltas durante mucho tiempo en torno a la provocación, sin comprender que la obra de Arrabal es una obra de "séduction" (Glibota, 1993: 18). Sin duda, la preocupación esencial del autor, presente en toda su creación, el gran tema recurrente, es la problemática concreta del amor y su lugar en el mundo. Podríamos sintetizar este aspecto esencial de su obra afirmando que Arrabal emprenderá, tanto en su existencia como en su obra, una lucha personal contra toda la represión que los regímenes autoritarios, ya sean las autoridades militares o fascistas, ya sean las autoridades eclesiásticas afines, impusieron en su entorno social y cultural más inmediato. Se erigirá en cierto sentido en abanderado de las causas perdidas y defensor de los oprimidos, los marginados y todos aquellos a los que nuestra sociedad califica de monstruos.

Como hemos intentado demostrar, el autor muestra sin ambages los grandes fenómenos de la vida, como la sexualidad, el amor y la muerte, aparte de una presencia constante de cuerpos y prácticas disidentes. Por otra parte, pone de manifiesto todos los fantasmas presentes en cualquier psique como el incesto, el sadomasoquismo, la escatología o el voyerismo. Arrabal pretende a toda costa dar una imagen plural, una visión múltiple de la sexualidad, aunque desde la perspectiva actual se pueda argumentar que reproduce ciertos estereotipos en torno al deseo homosexual. En este sentido, su obra ilustra continuamente una clara acti- 
tud comprometida al reivindicar lo que se condena y defender lo que se censura, con el fin de devolvernos una imagen poco tranquilizadora de nosotros mismos.

Le théâtre et les romans d'Arrabal, c'est la Loi du Désir, la Loi de l'Amour, c'est l'aveu
de nos terreurs, de notre solitude, de notre propre infantilisme, de notre étonnement
devant le monde et devant les adultes insensés que certains veulent être. Le narcissisme
d'Arrabal, multipliant les images de lui-même nous renvoie notre propre image, peu
rassurante, et cet étonnement devant ce que nous sommes ou pouvons être. (Fedoroff,
1993: 144)

\section{Referencias bibliográficas}

Arrabal, Fernando. 1958. Théâtre I: Oraison. Les Deux Bourreaux. Fando et Lis. Le Cimetière des Voitures. Paris, Julliard (coll. Les lettres nouvelles).

Arrabal, Fernando. 1963. La Pierre de la Folie. Paris, Julliard.

Arrabal, Fernando. 1967. “L'Architecte et l'Empereur d'Assyrie” in Arrabal, Fernando. Théâtre V. Théâtre Panique. Paris, Christian Bourgois.

Arrabal, Fernando. 1967. "La Communion solennelle. Cérémonie panique" in Arrabal, Fernando. Théâtre V. Théâtre Panique. Paris, Christian Bourgois.

Arrabal, Fernando. 1969. "Le Jardin des délices" in Arrabal, Fernando. Théâtre VI. Paris, Christian Bourgois.

Arrabal, Fernando. 1969. "Une tortue nommée Dostoïevsky" in Arrabal, Fernando. Théâtre VI. Paris, Christian Bourgois.

Arrabal, Fernando. 1969. “...Et ils passèrent des menottes aux fleurs” in Arrabal, Fernando. Théâtre VII. Paris, Christian Bourgois.

Arrabal, Fernando. 1970. “Ars Amandi (Opéra panique)” in Arrabal, Fernando. Théâtre VIII. Paris, Christian Bourgois.

Arrabal, Fernando. 1976. "Jeunes barbares d'aujourd'hui” in Arrabal, Fernando. Théâtre $X$. Paris, Christian Bourgois.

Bataille, Georges. 1985 [1957]. "L’Érotisme”. Paris, Les Éditions de Minuit (coll. Arguments).

Cantalapiedra, Fernando \& Francisco Torres Monreal. 1997. El teatro de vanguardia de Fernando Arrabal. Kassel, Reichenberger.

Castilla del Pino, Carlos. 1973. Introducción al masoquismo. Madrid, Alianza Editorial (col. El libro de bolsillo).

Chesneau, Albert \& Ángel Berenguer. 1978. Entretiens avec Arrabal: plaidoyer pour une référence. Grenoble, Presses Universitaires. 
Chevalier, Jean \& Alain Gheerbrant. 1989 [1969]. Dictionnaire des symboles. Mythes, rêves, coutumes, gestes, formes, figures, couleurs, nombres. Paris, Robert Laffont/Jupiter.

ÉvRARD, Franck. 2001. De la fellation dans la littérature. Bordeaux, Le Castor Astral.

EsPinASSE, Françoise. 1969. "Entretien avec Arrabal” in Arrabal, Fernando. Théâtre III. Le Grand Cérémonial. Cérémonie pour un Noir assassiné. Paris, Christian Bourgois.

Federoff, Michel. 1993. "Le poète enfant" in Glibota, Ante. Arrabal Espace. s.l., Studio di Val Cervo (P.A.C).

Glibota, Ante. 1993. Arrabal Espace. s.1., Studio di Val Cervo (P.A.C).

Hillman, James. 1979 [1972]. Pan et le cauchemar. Paris, Imago.

IsASI Ángulo, Amando Carlos. 1974. Diálogos del teatro español de la postguerra. Madrid, Ayuso.

Lamare, Patrice. 2000. "Arrabal (Fernando)" in Cousin, Philippe (sous la direction de). Encyclopédie du sadomasochisme. Paris, La Musardine.

Mayne, Gilles. 2001. Pornographie, violence obscène, érotisme. Paris, Descartes \& Cie.

Schiffres, Alain. 1969. Entretiens avec Arrabal. Paris, Pierre Belfond.

Torres Monreal, Francisco. 1986. “Introducción” in Arrabal, Fernando. Teatro pánico. Madrid, Cátedra. 